\title{
Revista de Historia de América, núm. 155, julio-diciembre, 2018
}

Kevin Aréchiga del Río

http://orcid.org/oooo-0001-8769-4364

Centro de Investigación y Estudios Superiores en

Antropología Social, unidad Peninsular, México

kevin_arechiga@comunidad.unam.mx

Revista de Historia de América, núm. 155, julio-diciembre, 2018, 240 pp. ISSN o034-8325 (Instituto Panamericano de Geografía e Historia).

\section{Un homenaje a Silvio Zavala, la propuesta de Revista de Historia de América}

El número 155 de la Revista de Historia de América, con motivo de su 80 aniversario, rinde homenaje a su fundador: Silvio Zavala (1909-2014). En esta edición hay, cronológicamente, ocho estudios que analizan varias facetas de la obra de Zavala entre 1930 y 1950, así como dos panorámicas de sus contribuciones a la Historia y la historiografía. Con una finalidad más analítica que narrativa, esta reseña prescinde del criterio temporal para estudiar las colaboraciones partiendo de sus intereses específicos. Así, revisaremos primero las ideas más importantes de los capítulos interesados en sus aportaciones a la institucionalización de la disciplina para después examinar diferentes aproximaciones a su obra.

Para Roberto Fernández, las revistas y los centros de investigación han sido puntos de partida privilegiados en el estudio de los intelectuales latinoamericanos. Sin embargo, la historia editorial y académica no agota la trayectoria intelectual de los pensadores; por el contrario, es preciso atender a sus motivaciones personales y

\section{(c) (i) (3)} 4.0 Internacional

Secuencia. Reseñas, 2021

http://secuencia.mora.edu.mx

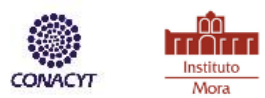


sus espacios de sociabilidad. Es en estos lugares donde se gestan, además de revistas, libros y otras publicaciones, instituciones y empresas de mayor calado. Esta es la premisa fundamental de la que parte el autor de "Silvio Zavala y la historiografía americana. Una vida de vínculos intelectuales" para analizar la trayectoria intelectual del historiador yucateco en su estancia española y la materialización en México de los vínculos personales allí establecidos, tanto en el Colegio de México como en el Programa de Historia de América. Esta mirada sobre la vida personal de Zavala, además de echar luz sobre sus aportaciones más conocidas a la institucionalización disciplinar en México, permite delinear continuidades entre los problemas personales de Zavala (económicos y legales) y su trabajo como historiador desde su llegada a la UNESCO.

Jesús Iván Mora Muro, por otro lado, presenta en el artículo titulado "Silvio Zavala y la institucionalización / profesionalización de la historia en México, 19331950" un estado de la cuestión pertinente para los interesados en la historia de la institucionalización de la disciplina en el país, y no exclusivamente para los estudiosos de Silvio Zavala. Luego de presentar las contribuciones hechas en este campo del conocimiento, el autor toma una decisión metodológica para estudiar al historiador yucateco al definir la profesionalización como "el proceso en el cual los especialistas o expertos de un saber son reconocidos socialmente por sus capacidades y conocimientos que son validados por instituciones oficiales que otorgan un título universitario. El profesional, para sintetizar, vive de la disciplina en que ha sido instruido" (p. 62). Esta definición, llevada hasta sus últimas consecuencias, permite concluir a Mora que Silvio Zavala no dio los primeros pasos de la institucionalización disciplinar en México, pues a su llegada de España "encontró las condiciones institucionales necesarias para su desenvolvimiento como historiador" (p. 63). Asimismo, esta lectura del pasado contextualiza las disputas historiográficas de la primera mitad del siglo XX dentro de las luchas de poder entre grupos antagónicos, encarnados en diferentes instituciones, por hacerse con mayor capital dentro del campo de la ciencia. 
También interesada en las aportaciones a la institucionalización disciplinar de Zavala, Erika Pani analiza en "Silvio Zavala y la Historia de América. Un juego de escalas" el Programa de Historia de América y la Revista de Historia de América. Según Pani, la Revista fue una iniciativa académica encaminada hacia la consolidación de un proyecto político, pues se trataba de un esfuerzo durante el periodo de entreguerras para promover la paz y la colaboración entre los países del continente. Así se publicaron investigaciones sobre el pasado colonial de América, información de diferentes archivos y descubrimientos de documentos para los docentes universitarios de Estados Unidos, así como para la comunidad de estudiosos que querían profesionalizarse en América Latina. Fiel al espíritu del homenajeado, la autora no se conforma con loar las pretensiones de tan ambicioso proyecto, sino que lo critica rigurosamente, poniendo en la mesa la poca atención prestada a las excolonias ajenas a los dominios hispanos y la ausencia de una narrativa o hilo conductor capaz de consolidar un objeto de estudio coherente frente a la heterogeneidad continental.

Una lectura novedosa de la obra de Zavala la propone Andrés Lira en "Revolución y Constitución en la obra de Silvio Zavala, 1930-1932", donde se enfoca en un corpus rico, mas poco estudiado. Para el autor, los trabajos de Zavala en esos años fueron el preludio de la obra historiográfica que estaba por venir. Antes de partir a España, durante la etapa mexicana (según Lira) Zavala se interesó en la realidad concreta del país. Por ello se preguntó por el papel de los legisladores en el México que él experimentó y buscó estudiar la todavía reciente Revolución a la luz del Derecho Constitucional. Una vez en España, Zavala fungió como periodista político o corresponsal en los medios mexicanos de los acontecimientos sociopolíticos durante la República. Este artículo acierta por su trabajo hemerográfico y la inclusión de atinadas citas que permiten esbozar su producción en aquel entonces, así como por la identificación de similitudes entre este primer periodo del pensamiento de Zavala y su madurez. Sin embargo, se echa de menos una reflexión sobre los cambios de tono empleados por el yucateco, dependiendo del tema a tratar y el medio de publicación. De esta manera, queda abierta la pregunta 
sobre los estilos, las estrategias argumentativas y las posiciones ideológicas del joven Zavala según el público al que se dirigió.

Francisco Quijano busca hacer justicia a la multifacética obra del historiador yucateco al afirmar en "La Filosofía de la Conquista de Silvio Zavala. Apuntes y límites de una historia de las ideas" que no toda su producción es afín al positivismo o cientificismo que le achacan. Por el contrario, escribió obras preocupadas por la filosofía y las ideas políticas de corte ensayístico, en donde resaltan la perspectiva reflexiva y los juicios de valor. Para mejor comprender la propuesta zavaliana en la Filosofía de la Conquista y obras similares, es preciso ponerlas en el contexto de la doble controversia en la que participó. Desde la perspectiva historiográfica, Zavala buscaba reivindicar a la Colonia como objeto de estudio digno, desmintiendo las doctrinas liberales que veían en aquel periodo un lastre para el devenir de las naciones latinoamericanas. Revalorar positivamente a la Colonia, por otra parte, tuvo implicaciones éticas y políticas que apuntaban hacia encontrar en el pasado colonial una solución "al problema colonial moderno" (p. 92). Quijano destaca los límites y la aplicación de la Historia tradicional de las Ideas por Zavala y sus resultados. Le reprocha con justicia la ausencia de la valoración de aspectos centrales dentro del pensamiento de los autores estudiados por Zavala, así como la omisión del siglo XVII y su preferencia por la Ilustración francesa en el siglo XVIII. Como contraste, un acierto de Zavala fue diferenciar las posturas de Bartolomé de Las Casas de las elaboradas por los pensadores ilustrados.

Alberto Enríquez Perea, en "El pensar quiroguiano en la obra de Silvio Zavala", destaca que don Silvio estuvo siempre interesado en la vida y obra del primer obispo de Michoacán. Menos interesado en la vida íntima religiosa de este español, Zavala dejó de lado la búsqueda de sus santos favoritos para dar cuenta de la actitud de Vasco de Quiroga frente a conquistadores y naturales americanos. Para él, América representaba una oportunidad sin precedentes de refundar los valores de la Iglesia Católica lejos de la corrupción, desobediencia y ambición europeas. Quiroga fue para Zavala un ejemplo de lo que el Nuevo Mundo ocasionaba en la 
cabeza de los europeos, pero también un motivo de esperanza en la fe humanista traída del Viejo Mundo, algo que sin duda marcó su propio pensamiento.

En "Silvio Zavala y la interpretación sobre el pasado nacional: México frente al mundo", Elmy Lemus estudia la propuesta de historia general del país elaborada por Zavala en su faceta como intelectual y funcionario. Para Lemus, esta parte de la obra zavaliana (escrita entre 1946 y 1955) fue "una carta de presentación del país ante organismos internacionales" (p. 159). Mientras fue funcionario cultural o diplomático, Zavala se esforzó por mostrar un país con identidad propia cuyo fundamento primordial era el mestizaje. El yucateco "trataba de mostrar a Europa una cara positiva de México, menos centrada en los conflictos y desgracias que un siglo de conflictos internos habían sido noticia en el Viejo Continente" (p.173). Con una fuerte influencia quiroguiana, Zavala confiaba en que América, partiendo de la herencia hispana, podría resolver los problemas del mundo de la posguerra.

Una apuesta por la vigencia de la obra de Silvio Zavala la hace Mario Enrique Fuente en "Armamento y tributo indígena: una aportación de la Historia de la Conquista desde los documentos jurídico-administrativos”. Aquí, el autor defiende la necesidad de una relectura de los estudios y las fuentes referentes al armamento hispano en la Conquista, pues buena parte de la crítica sobrevalora el genio militar hispano y su superioridad tecnológica. Contra lo que establecen las fuentes más usadas (crónicas y códices), los documentos jurídico-administrativos apuntan a que tan solo una décima parte de la hueste hispana vestía armadura de metal debido, entre otros motivos, a que no se fundían metales en el Nuevo Mundo y su importación tenía costos elevados. Para suplir esta carencia los conquistadores recurrieron a las aleaciones y armas nativas. Gracias a un pase de lista del siglo XVI es posible saber que nueve de cada diez conquistadores hispanos usaban, en lugar de metal, sayos de algodón, rodelas de carrizo entretejido, gorriones de cuero y calzado nativo. Lamentablemente la representación gráfica de la indumentaria de los conquistadores hispanos (retomada de Richard Flint) no está a la altura de la exhaustividad de la descripción hecha por el autor. En vista de las posibilidades que ofrece hoy la tecnología, se echan de menos en el esquema los nombres de los objetos estudiados. Obviando esa carencia, el artículo demuestra con creces la vigencia de la 
obra de Zavala en la actualidad y abre la posibilidad de reexaminar con este enfoque diferentes verdades históricas que se dan por sentadas en la actualidad.

Cierran este número de la revista un "Homenaje" de Patricia Galeana y una "Vuelta al cliché" de Germán Luna. En el primero, la discípula y amiga de Zavala hace una síntesis de la trayectoria intelectual de Zavala. Destacan la línea del tiempo con sus aportaciones más trascendentales y la constatación de que su vida entera "es un ejemplo de autodisciplina, de tenacidad y de trabajo, prescindiendo de cualquier otra satisfacción que no fuera el estudio" (p. 196). En el segundo, Luna explica que la identificación de Zavala como positivista fue un juicio que él mismo impulsó, pues coincidía con Ranke cuando pugnaba por la construcción de una ciencia objetiva y empírica. Sin embargo, y a la luz de entrevistas poco conocidas, Luna da cuenta de cómo Zavala no fue sordo a las reflexiones historicistas, sino que éstas propiciaron un viraje en su pensamiento. Fue así como Zavala admitió que cada generación proyecta sobre el pasado sus propios intereses e ideas, al mismo tiempo que defendió la existencia de una verdad histórica no sujeta a tergiversaciones. Lejos de dar respuestas concluyentes o buscar agotar la obra de Silvio Zavala, este número de Historia de América invita a plantear nuevas preguntas a la obra del yucateco y a reexaminar antiguos problemas desde sus aportaciones. No cabe duda de que este clásico sigue vivo y está en condiciones de aportar a la comprensión del pasado colonial del continente. 